\title{
INTERPRETAÇÃO JURÍDICA PARA LÍNGUA DE SINAIS: REPENSANDO AS DIMENSÕES HISTÓRICAS, SOCIOLÓGICA, POLÍTICAS E DE FORMAÇÃO PROFISSIONAL
}

\author{
Rosemeri Bernieri de Souza 1 \\ 1Universidade Federal de Santa Catarina, Florianópolis, Santa Catarina, Brasil
}

\begin{abstract}
Resumo: Neste artigo, proponho discutir a interpretação jurídica entre línguas de sinais e línguas faladas sob os aspectos históricos, sociológicos, políticos e de formação profissional. Dentro dessa perspectiva, este trabalho se caracteriza como uma pesquisa exploratória, pela qual se estabelece o estado da arte dessa especialidade. A partir de textos legais e projetos de formação, que são discutidos e interpretados com base nos argumentos de autores como Santos (2016); Santos e Francisco (2018); Russell (b); Roberson, Russell e Shaw (2011), é possível elencar as necessidades e dificuldades que devem ser contornadas por políticas de tradução e políticas linguísticas adequadas. Chega-se, então, à conclusão de que é imprescindível: (i) reparar as incoerências que se encontram nos dispositivos legais; (ii) construir políticas de tradução juntamente com os profissionais, agentes surdos e entidades que os representam; (iii) favorecer a profissionalização, a fim de responder às necessidades e dificuldades encontradas na prática dos intérpretes. Este trabalho reforça, assim, outros discursos e esforços que têm sido realizados nesse âmbito, acrescentando informações à construção de um design curricular que contemple as especificidades dessa especialização, de forma que o profissional adquira confiança e competências para desempenhar um trabalho capaz de promover a justiça social e o direito linguístico.
\end{abstract}

Palavras-chave: Interpretação; Língua de Sinais; Esfera Jurídica; Formação Profissional; Currículo 


\title{
LEGAL INTERPRETATION TO SIGN LANGUAGE: RETHINKING THE HISTORICAL, SOCIOLOGICAL, POLITICAL AND VOCATIONAL TRAINING DIMENSIONS
}

\begin{abstract}
In this article, I propose to discuss the legal interpretation between sign languages and spoken languages under the historical, sociological, political and vocational training aspects. From this perspective, this work is characterized as an exploratory research, by which the state of art of this specialty is established. From legal texts and training projects, which are discussed and interpreted based on the arguments of authors such as Santos (2016); Santos and Francisco (2018); Russell (b); Roberson, Russell and Shaw (2011), it is possible to list the needs and difficulties that must be overcome by appropriate translation policies and language policies. It is then concluded that it is essential: (i) to repair the inconsistencies found in legal documents; (ii) to create translation policies together with the professionals, deaf agents and entities that represent them; (iii) to promote professionalism in order to respond to the needs and difficulties encountered in the practice of interpreters. This work thus reinforces other discourses and efforts that have been made in this area, adding information to the construction of a curricular design that contemplates the specificities of this specialization, so that the professional acquires the confidence and competences to carry out a work capable of promoting social justice and linguistic rights.
\end{abstract}

Keywords: Interpretation; Sign Language; Legal Sphere; Professional Qualification; Curriculum

\section{Introdução}

A interpretação é uma prática milenar que, ao longo do desenvolvimento histórico das sociedades, tem favorecido as interações face a face entre grupos ou pessoas que não compartilham a mesma língua. Entretanto, trata-se de uma atividade, cujas reflexões acadêmicas e prático-teóricas são relativamente recentes e cuja origem, enquanto campo disciplinar, não é compartilhada por todos os autores. Para Günther Haensch (1965), a Conferência de Berlin, de 1878 , é que foi o palco da emergência do reconhecimento da 
interpretação como uma profissão. Baigorri-Jalón (2014) defende que sua origem se deu na Conferência da Paz de Paris, em 1919. Para Delisle e Woodsworth (2012), os julgamentos dos crimes de guerra após a Segunda Guerra Mundial, entre 1945 e 1948, podem ser considerados os prolegômenos do campo da interpretação.

Os três contextos citados são exemplos típicos de interpretação de conferência, uma vez que foram cenários de encontros multilíngues de grande envergadura. De todos, os julgamentos de $\mathrm{Nu}$ remberg (1945-1946) e de Tóquio (1946-1948) constituem-se em exemplos excepcionais de interpretação de tribunal, porém, a configuração de trabalho nesses dois contextos foi muito diferente da demanda atual.

A interpretação de tribunal (court interpreting) é muitas vezes considerada sinônimo de interpretação jurídica (legal interpreting), interpretação forense (forensic interpreting) e interpretação judiciária (judiciary interpreting) (Lee), porém, é preciso esclarecer que a interpretação de tribunal ou judicial faz parte da categoria mais geral chamada de interpretação jurídica (Mathers), que é um tipo de interpretação comunitária que abrange a atuação em várias instâncias ligadas direta ou indiretamente ao sistema judiciário: audiências de conciliação ou mediação, audiências de instrução e julgamento, audiências de justificação, inquéritos policiais, sessões de atendimentos em penitenciárias, cartórios, escritórios de advocacia, juizados, conselhos, entre outros.

Com o aumento da mobilidade humana, das atividades comerciais, culturais e diplomáticas, a interpretação passou a ser uma necessidade em diversos universos sociais e geográficos, passando a constar indiretamente na lista dos direitos humanos, uma vez que a língua não pode limitar ou colocar barreiras na capacidade de gozar dos direitos e liberdades dos seres humanos (Declaração Universal dos Direitos Humanos).

Entretanto, afora essa dimensão mais global e internacional, as barreiras linguísticas podem constituir um entrave dentro de um mesmo país, pelo simples fato de que o monolinguismo é uma invenção que não corresponde com a realidade de nenhuma nação. 
Inseridos num contexto multilíngue, há grupos indígenas, imigrantes, refugiados e surdos que muitas vezes não são fluentes nas línguas oficiais dos países em que se encontram.

Evidentemente, esse contato entre diferentes línguas não é uma relação sem tensões e conflitos, sobretudo quando as interações precisam ser mediadas em contextos jurídicos. De fato, o meio jurídico não é um espaço de circulação muito almejado pelos agentes sociais. Salvo por opção profissional, recorre-se a esse domínio para resolver divergências entre as partes em um processo judicial, esclarecer ou defender-se contra acusações, estabelecer acordos em transações comerciais ou familiares, depor a favor ou contra outrem etc., ou seja, todas essas motivações estão relacionadas ao gozo de direitos como liberdade, defesa, segurança, mas também relacionadas ao exercício dos deveres e da cidadania.

Os direitos e deveres humanos podem ser consideravelmente restringidos quando as partes envolvidas nas instâncias jurídicas não possuem uma língua em comum. Nesse caso, o acesso aos serviços e direitos básicos, como os que foram citados, passam pelo direito à acessibilidade que se efetiva pela eliminação das barreiras linguísticas. Assim, no capítulo III do Código de Processo Civil, em seu artigo 149, os intérpretes e tradutores são arrolados como "auxiliares da Justiça".

A preocupação com a qualidade e a formação para a interpretação jurídica é muito recente, sendo ainda alvo de confusões. A primeira é a falsa premissa de que toda pessoa bilíngue é apta a interpretar e traduzir. A segunda crença errônea é que, após formado, um intérprete ou tradutor pode trabalhar em qualquer área do conhecimento (Reckelberg). Primeiramente, a profissão de intérprete e tradutor requer, além de sua competência bilíngue, o aperfeiçoamento de técnicas, conhecimentos e competências como qualquer outra atividade profissional. Em segundo lugar, assim como um médico precisa se especializar no domínio em que vai atuar - cirúrgico, pediátrico, clínico, entre outros - intérpretes e tradutores precisam de especialização para atuar nas diferentes instâncias sociais: médica, educacional, jurídica, assistência social etc. Por 
isso, a presença de intérpretes em diferentes espaços bilíngues ou multilíngues demanda o desenvolvimento de diferentes políticas de tradução, diferentes políticas linguísticas e diferentes habilidades e conhecimentos, de modo, "[...] a transformar os intérpretes em verdadeiros peritos nas suas esferas de atuação" (Reckelberg 79).

Em se tratando de atuação em contexto jurídico, o Código de processo penal brasileiro, regulamentado pelos dispositivos do Decreto-lei n. 3.689/1941, em seu artigo 281, ressalta que "Os intérpretes são, para todos os efeitos, equiparados aos peritos”. Isso significa que a mediação interlingual em meio judicial penal, com extensão a qualquer meio jurídico, é uma grande responsabilidade que exige preparo, ética profissional (como em qualquer área) e competências específicas, como a linguística, a tradutória e de interpretação, a terminológica, a técnica, a instrumental, entre outras.

Anteriormente, os surdos foram citados dentre os grupos que, apesar de compartilharem espaços sociais de um mesmo território com os não-surdos, podem ter suas ações, atividades e direitos civis e humanos reduzidos ou completamente impedidos devido à barreira linguística. Para dirimir ou minimizar os impactos dessa problemática, estudos acadêmicos têm sido realizados, a fim de organizar a especialidade e implementar políticas que garantam o gozo e o acesso aos direitos no exercício da cidadania.

Portanto, neste trabalho, a interpretação jurídica para surdos e em língua de sinais é abordada em seus aspectos histórico, social, político e de especialização profissional, adotando-se como base de discussão textos legislativos e teóricos e projetos de formação. Para o desenvolvimento dessa proposta, o presente artigo será organizado da seguinte forma: A segunda seção versará sobre como os formuladores de leis responderam à necessidade de interpretação para surdos em contexto jurídico em diferentes épocas. A terceira seção aprofundará a noção de interpretação como direito linguístico, ressaltando a necessidade de minimizar os conflitos ideológicos e as incompreensões da intepretação jurídica. Na quarta seção, será discutida a formação profissional voltada à tradução e interpretação jurídica. Por fim, serão feitas algumas considerações à guisa de conclusão. 


\section{As leis que incidem sobre o intérprete para surdos na instância jurídica}

Santos (2016) relata que um material comemorativo pelos 150 anos do Instituto Nacional de Educação de Surdos, de 2008, apresenta a imagem de uma carta datada de 1907, cujo conteúdo se refere à primeira solicitação de intérprete de tribunal para surdo aqui no Brasil. Entretanto, o primeiro texto legal brasileiro a citar a mediação de intérprete em processos civis envolvendo surdos é o Decreto $\mathrm{n}^{\circ}$ 8.332, de 3 de novembro de 1910, que aprova o Código do Processo Civil e Comercial.

Remetendo-se à arbitragem em transações comerciais, o capítulo $\mathrm{X}$ apresenta ambiguidades, pois, enquanto no parágrafo $3^{\circ}$ do artigo 128, "Os surdos-mudos de nascimento, que não tiverem recebido a competente educação" não podem ser arrolados como testemunhas, logo abaixo permite-se sua participação pela mediação de um intérprete. Deduz-se que a referida "educação" se trata, grosso modo, de uma habilidade linguística que possibilite a comunicação entre as partes. Entretanto, a possibilidade de o surdo ser interpretado só encontra respaldo após abrir-se um precedente no artigo 132: "Si alguma testemunha não souber falar a lingua portugueza, o juiz nomeará interprete, que prometterá traduzir fielmente as perguntas e respostas" (sic). Então, de forma a garantir a "igualdade de condições", o artigo 133 declara que: "Do mesmo modo se nomeará interprete para traduzir a linguagem mimica do surdo-mudo" (sic). Esse trecho é, em seguida, complementado pelo parágrafo único com a seguinte menção: " $\mathrm{Si}$, porém, o surdo-mudo souber ler e escrever, ser-lhe-ha tudo perguntado por escripto, e por escripto responderá" (sic).

O Código do Processo Civil foi posteriormente atualizado pelo Decreto $\mathrm{n}^{0} 16.752$, de 31 de dezembro de 1924 e, em seu artigo 186, a exemplo do texto anteriormente mencionado e usando os mesmos termos, reitera o direito do surdo de ser mediado por intérprete em processos jurídicos, ressalvando a prioridade da comunicação por escrito, caso o surdo saiba ler e escrever.

Cad. Trad., Florianópolis, v. 40, n 2, p. 252-281, mai-ago, 2020. 
Não se pretende aqui fazer uma análise textual profunda nem discutir as nomenclaturas como "surdo-mudo" ou "linguagem mímica", uma vez que as terminologias e os ideários sociais equivocados em relação aos surdos e à língua de sinais persistem até hoje, é evidente que na data de produção desses textos, o desconhecimento sobre a identidade surda e sua língua era ainda maior. O que se pretende ressaltar é o fato de que a figura do intérprete para mediar a comunicação dos surdos com as partes que se encontram em juízo é mencionada por esse instrumento legal na primeira década do século XX.

Alguns anos mais tarde, o Decreto-Lei $n^{0} 3.689$, de 3 de outubro de 1941, que estabelece o Código de Processo Penal, apresenta alguns dispositivos sobre como se deve proceder no interrogatório de pessoas surdas:

\begin{abstract}
Art. 192. O interrogatório do mudo, do surdo ou do surdomudo será feito pela forma seguinte:

I - ao surdo serão apresentadas por escrito as perguntas, que ele responderá oralmente;

II - ao mudo as perguntas serão feitas oralmente, respondendo-as por escrito;

III - ao surdo-mudo as perguntas serão formuladas por escrito e do mesmo modo dará as respostas.

Parágrafo único. Caso o interrogando não saiba ler ou escrever, intervirá no ato, como intérprete e sob compromisso, pessoa habilitada a entendê-lo.
\end{abstract}

Todos os dispositivos acima, tiveram a redação dada pela Lei $\mathrm{n}^{\mathrm{o}} 10.792$, de $1^{\mathrm{o}}$ de dezembro de 2003 . Isso significa que, mesmo após a Lei de Libras de 2002, o texto continua inalterado e o intérprete só é demandado quando a comunicação por outros meios se torne ineficaz para os propósitos do inquérito. Vale ressaltar que a noção de intérprete pode não estar atrelada ao sentido de "profissional capacitado", mas, sim, uma "pessoa habilitada a dar significado", em outras palavras, a alguém que conhece o interrogando, como um amigo, um familiar ou um professor. 
Coincidência ou não, o texto em questão é muito semelhante ao texto do artigo 333 do Código de Instrução Criminal francês datado de 1808. Nele consta que

Se o acusado for surdo-mudo e não souber escrever, o presidente nomeará automaticamente a pessoa com maior probabilidade de conversar com ele como sua intérprete. O mesmo se fará com respeito à testemunha surda-muda. [...]

No caso em que o surdo-mudo possa escrever, o escrivão escreverá as perguntas e observações que lhe serão feitas; elas serão entregues ao acusado ou à testemunha, que dará suas respostas ou declarações por escrito. Tudo será lido pelo escrivão. ${ }^{1}$

Essa semelhança pode estar relacionada ao fato de que alguns códigos brasileiros tomaram como base os códigos europeus, como é o caso do código civil que foi baseado no Código de Napoleão, o código civil francês (Capanema-Souza, 2004). Essa comparação indica que as leis revelam muito dos aspectos históricos de um país e de suas relações diplomáticas, além de informar sobre que tipos de atividades eram desenvolvidas socialmente em determinada época. Assim, o documento legal francês, de 1808, atesta que surdos se apresentavam em tribunais e eventualmente precisavam da mediação de um intérprete.

Entretanto, esse documento não é a prova mais antiga da evidência da mediação de intérpretes para surdos em contextos jurídicos. Recu-

\footnotetext{
${ }^{1} \mathrm{Si}$ l'accusé est sourd-muet et ne sait pas écrire, le président nommera d'office pour son interprète la personne qui aura le plus d'habitude de converser avec lui. Il en sera de même à l'égard du témoin sourd-muet.

[...]

Dans le cas où le sourd-muet saurait écrire, le greffier écrira les questions et observations qui lui seront faites ; eles seront remises à l'accusé ou au témoin, qui donneront par écrit leurs réponses ou déclarations. Il sera fait lecture du tout par le greffier.
}

Cad. Trad., Florianópolis, v. 40, $\mathbf{n}^{0}$ 2, p. 252-281, mai-ago, 2020. 
perando dados encontrados por Stone (2012), Napier (2015) informa a existência de documentos do tribunal Otomano que datam de 1600. $\mathrm{Na}$ Inglaterra, a primeira atuação de intérpretes de língua de sinais em tribunais teria ocorrido em 1771, segundo a pesquisa realizada por Stone e Woll (2008). Os autores relatam que, em 1778, a interpretação de tribunal passou a ser formalmente estabelecida nesse país.

Ainda na instância jurídica brasileira, mas agora relacionada às causas trabalhistas, o Decreto-lei n ${ }^{\circ} 5.452$ de $1^{\circ}$ de maio de 1943, que aprova a Consolidação das Leis do Trabalho, em seu artigo 819 , estabelece que

O depoimento das partes e testemunhas que não souberem falar a língua nacional será feito por meio de intérprete nomeado pelo juiz ou presidente. $\S 1^{\circ}$ Proceder-se-á da forma indicada neste artigo, quando se tratar de surdo-mudo, ou de mudo, que não saiba escrever.

Como é possível verificar, os dispositivos insistem na prioridade da escrita, ou seja, na expressão em uma segunda língua e, em caso de falha nesse tipo de comunicação, o intérprete seria convocado. No entanto, considerando que a profissão não era reconhecida na época, os intérpretes mencionados nas leis eram pessoas bilíngues que desconheciam as especificidades da área. Isso certamente levou à ocorrência de várias injustiças, como a condenação de réus inocentes ou a soltura de réus culpados.

Foram necessários longos anos até que uma das línguas de sinais existentes no Brasil fosse reconhecida e que os ideários sociais a respeito do surdo mudassem razoavelmente. Entretanto, o reconhecimento da profissão do tradutor intérprete tem menos de uma década. Um processo moroso haja vista que há um espaço de exatamente cem anos entre a primeira menção ao intérprete de "linguagem mímica do surdo-mudo", no documento de 1910, até a Lei que Regulamenta a profissão de Tradutor e Intérprete da Língua Brasileira de Sinais - LIBRAS. 
A Lei n. ${ }^{\circ} 12.319$, de $1^{\circ}$ de setembro de 2010, em seu artigo $6^{\circ}$, define as atribuições do tradutor e intérprete, no exercício de suas competências, citando, no item $\mathrm{V}$, a prestação de serviços em depoimentos em juízo, em órgãos administrativos ou policiais. Dispõe, portanto, sobre uma demanda antiga, mas que só foi possível após uma completa mudança na concepção de quem é o surdo e da língua de sinais para que a política linguística fosse estabelecida.

O novo Código de Processo Civil, estabelecido pela Lei $\mathrm{n}^{\mathrm{o}}$ 13.105, de 16 de março de 2015, também traz mudanças em relação ao profissional intérprete de língua de sinais. De fato, a seção IV, que trata do intérprete e do tradutor, define que:

\begin{abstract}
Art. 162. O juiz nomeará intérprete ou tradutor quando necessário para:

I - traduzir documento redigido em língua estrangeira;

II - verter para o português as declarações das partes e das testemunhas que não conhecerem o idioma nacional; III - realizar a interpretação simultânea dos depoimentos das partes e testemunhas com deficiência auditiva que se comuniquem por meio da Língua Brasileira de Sinais, ou equivalente, quando assim for solicitado (grifo nosso).
\end{abstract}

Ao acrescentar o item III, que incide sobre a interpretação da Libras, o novo código responde à realidade atual, o que deveria ser feito em vários outros textos legislativos. Porém, peca-se em indicar a interpretação simultânea como modalidade, visto que a interpretação consecutiva, ou ambas em intermitência, podem ser empregadas, dependendo da necessidade. Outro equívoco foi utilizar somente a nomenclatura "deficiência auditiva", pois há muitos sinalizantes que não se identificam com esse apelo, preferindo ser denominados como surdos, conforme o sentido cultural dado a esse termo.

Leis são importantes, pois consistem em princípios norteadores que incidem sobre fatos sociais. Entretanto, a existência de leis nem sempre assegura, de forma concreta e efetiva, os direitos individuais e coletivos dos cidadãos, pois elas são passíveis de in- 
terpretações subjetivas e generalizações. Na próxima seção, será discutido o direito à interpretação jurídica como um princípio de defesa dos direitos humanos e de políticas linguísticas.

\section{Interpretação jurídica e as políticas em defesa dos direitos humanos}

O sintagma "interpretação jurídica" apresenta ambiguidade no sentido de que ele é veiculado em pelo menos dois domínios: o do Direito e o dos Estudos da Tradução. No Direito, ele foi teorizado por Kelsen (1998) e está relacionado ao modo de dar sentido às normas jurídicas (leis). Para os Estudos da Tradução, trata-se da prática de mediação interlingual em interações face a face na instância jurídica.

A preocupação com a recepção e significação das leis pelos surdos e a forma equivocada como eram tratados nas audiências de instrução e julgamento são documentalmente evidenciadas. Ferdinand Berthier, um surdo do século XIX, instruído no modelo educacional do famoso Instituto de Paris - portanto, um caso de sucesso, haja vista sua competência como articulador político em favor dos surdos e sua notoriedade no círculo intelectual e literário da sociedade francesa da época - não mediu esforços para tornar as leis acessíveis aos seus "irmãos". Nesse intuito, em 1868, ele escreveu "Le Code Napoleon, código civil do Império Francês, disponível para os surdos-mudos, suas famílias e os falantes no relacionamento diário com eles" (Berthier, 1-3). Ele desabafa nas primeiras páginas dessa obra dizendo:

Quantas vezes eu já experienciei, no calor de minhas atribuições, que um surdo-mudo, tão inteligente quanto se suponha, corre o risco de ser conduzido à presença da lei que ele viola sem o saber! Quantos não são vistos nas nossas sessões [...] absolvidos apesar da evidência de sua culpa! [...] Por outro lado, acontece que mais de um desses in- 
felizes é traduzido em tribunal [...] com mediadores que muitas vezes falham, com intérpretes que o acaso lhe dá, a quem compreende mal, e de quem nem sempre é compreendido. [...] As leis não são uma necessidade diária para todos os cidadãos? E mais do que qualquer outro, o surdo-mudo, jogado pela sua posição, até certo ponto, fora da sociedade, não precisa ser esclarecido nos princípios de nossas leis e especialmente em relação à parte da legislação que lhe diz respeito? (Berthier, 1-3) ${ }^{2}$

O que constatava Berthier, em seu contexto sócio-histórico, constitui ainda, apesar de passados 150 anos, a realidade de muitos países. Não é raro encontrar autores que atestam isso. Segundo Roberson, Russell e Shaw (66) “[...] há práticas no campo da interpretação da língua de sinais que podem obstruir o acesso legal para os participantes surdos" ${ }^{3}$. Russell ((b) 5) relata que em algumas jurisdições, agentes da polícia ou servidores de tribunais com pouca fluência em língua de sinais interpretam as sessões, salientando que "isso quase sempre leva a falhas de comunicação e ao potencial real de erros graves que afetam a pessoa Surda e os serviços que ela está tentando acessar" ${ }^{4}$.

${ }^{2}$ Que de fois n'ai-je pas éprouvé, au milieu de mes fonctions, qu'un sourd-muet, quelque intelligent qu'on le suppose, risque d'être placé en présence de la loi qu'il enfreint sans la connaître! Combien n'en voit-on pas dans nos sessions [...] acquittés en dépit de l'évidence de leur culpabilité ! [...] D'autre part, il arrive que plus d'un de ces infortunés est traduil devant un tribunal [...] avec des intermédiaires qui trop souvent lui font défaut, avec des interprètes que le hasard lui donne, qu'il comprend mal, et dont il risque de ne pas être toujours compris. [...] Les lois ne sont-elles pas une nécessité de chaque jour pour tous les citoyens? Et plus que tout autre, le sourd-muet, jeté par sa position, jusqu'à un certain point, em dehors de la société, n'a-t-il pas besoin d'être éclairé sur les principes de nos lois et surtout sur la partie de la législation qui le concerne? (tradução nossa)

${ }^{3}[\ldots]$ there are practices in the field of sign language interpreting that may obstruct legal access for Deaf participants.

${ }^{4}$ This almost always leads to miscommunications, and the very real potential for grave errors that have an impact on the Deaf person and the services that they are trying to access. 
Confrontados por essas problemáticas, alguns autores têm vinculado políticas de tradução à defesa das minorias linguísticas (Núñez; Santos e Francisco). Para Santos e Francisco (2941),

o termo 'políticas de tradução' engloba uma série de assuntos relevantes a serem discutidos e investigados não só no contexto acadêmico, mas também junto às entidades de classe e demais órgãos representativos dos tradutores.

Portanto, embora a implementação de políticas dependa de iniciativas governamentais e institucionais, políticas linguísticas e políticas de tradução podem ser realizadas de baixo para cima, consistindo em tomadas de posição estratégicas para a articulação de propostas que incidam sobre a necessidade social e comunitária. É preciso interpretar, trazer à tona significados e concepções implícitas e explícitas nos discursos e políticas historicamente institucionalizados, a fim de renegociar sentidos, enfraquecer os conflitos ideológicos, minimizar os impactos causados pelas relações de dominação e resistência e provocar efeitos que promovam a justiça social.

Santos e Francisco (2947) defendem que "políticas linguísticas não se reduzem às diretrizes legais", do mesmo modo, as leis e resoluções, da forma como são concebidas e formuladas, não tocam senão a ponta do iceberg do campo político e social e, para piorar, são formuladas sem consultas aos agentes que estão no centro dos fatos e práticas sociais. Tome-se como exemplo um ponto específico da Resolução 230, de 22 de junho de 2016, que “orienta a adequação das atividades dos órgãos do Poder Judiciário e de seus serviços auxiliares às determinações exaradas pela Convenção Internacional sobre os Direitos das Pessoas com Deficiência" (Brasil, 2016). O capítulo II, que trata das disposições relacionadas a todas as pessoas com deficiência, contém, na subseção III da seção I, recomendações sobre as comissões permanentes de acessibilidade e inclusão. O item $\mathrm{V}$ dispõe sobre a 
V - nomeação de tradutor e intérprete de Linguagem Brasileira de Sinais, sempre que figurar no processo pessoa com deficiência auditiva, escolhido dentre aqueles devidamente habilitados e aprovados em curso oficial de tradução e interpretação de Linguagem Brasileira de Sinais ou detentores do certificado de proficiência em Linguagem Brasileira de Sinais - PROLIBRAS, nos termos do art. 19 do Decreto 5.626/2005, o qual deverá prestar compromisso e, em qualquer hipótese, será custeado pela administração dos órgãos do Judiciário (grifos nossos);

Numa leitura cuidadosa, é possível identificar vários problemas na sua formulação, denunciando a forma leiga com que o assunto foi tratado. De imediato, o emprego do termo "linguagem" ao invés de "língua" - sem entrar na questão ideológica e conceitual que está implicada nessa escolha - está descompassado da expressão Língua Brasileira de Sinais adotada no decreto 5.626/2005, ao qual se refere. Outro equívoco foi citar a certificação do Prolibras, uma vez que, no referido decreto, essa certificação tinha a validade de 10 anos, tendo concluído esse prazo em 2015, portanto, antes mesmo de esta resolução ser redigida. O que é mais grave, no entanto, é o fato de achar que, por estar formado em um curso de tradução e interpretação ou possuir o certificado de proficiência, o profissional está apto a interpretar em diversos contextos. Como foi abordado na introdução deste artigo e será aprofundado a seguir. Enquanto "perito" e "auxiliar da justiça", um intérprete que pretende atuar na área jurídica, precisa estar instrumentalizado, habilitado e preparado para as particularidades do campo.

Diante desses descompassos e desiquilíbrios, é que políticas de tradução devem estar associadas a políticas linguísticas, uma vez que "a prática social da tradução é um palco privilegiado para se observar a ativação desse fazer linguístico-político" (Queiroz; Bagno; Monteiro 128). É por isso também que os aspectos ideológicos e de formação devem ser explorados criticamente nas políticas de tradução. 
Não basta assegurar a presença de um intérprete, é preciso investir na qualidade de sua atuação pois, admitir que intérpretes desqualificados prestem serviço sem compreender a terminologia e interpretar os significados culturais dos termos e expressões, consiste em uma violação aos direitos linguísticos e humanos. Por isso, é preciso abordar a formação com seriedade e compromisso.

\section{A formação profissional com especialização na tradução e interpretação jurídica}

São poucos os países que têm estabelecido um sistema de certificação para intérpretes jurídicos em línguas orais. Na Suécia, a primeira regulamentação da prática na área judicial foi iniciada em 1976, com a realização de um Exame de Autorização Estadual (Ozolins (a)). Segundo Lee (2015), um exame de certificação federal foi criado, em 1980, nos Estados Unidos, mas é restrito a poucas línguas. Na Austrália, a partir de 1980 nenhum profissional intérprete pode atuar no campo jurídico sem ter passado no exame de certificação específica ao domínio desejado (Ginezi). O Canadá adotou a certificação em 1978 (idem). Ozolins (b) menciona que uma das certificações mais completas em interpretação jurídica é desenvolvida na Dinamarca, realizada por uma formação de dois anos. De acordo com Ginezi (30)

Em muitos países, dentre eles o Brasil, os intérpretes de tribunal são aqueles aprovados em concursos públicos para tradutores juramentados. A maioria desses países, no entanto, não oferece treinamento para que o intérprete exerça sua função no tribunal.

Embora a certificação em tradução e interpretação de língua de sinais seja uma prática mais comum, certificações específicas para atuação nas instâncias jurídicas são raras. De fato, como foi visto 
anteriormente, a necessidade é antiga, a intervenção prática também, mas a qualidade da profissão só tem sido alvo de investigação há pouco mais de duas décadas.

No que tange às investigações da área, a partir de uma revisão da literatura, Roberson, Russell e Shaw (2011) destacam pesquisadores que abordaram diversos aspectos da interpretação jurídica em língua de sinais, tais como Brennan (1999); Fournier (1997); Miller (2001); Miller e McCay (1994); Nardi (2005); Russell (a); Stevens (2005); Tilbury (2005); Turner (1995); Turner e Brown (2001); Wilcox (2006) e sobre as dificuldades de acesso à dos surdos a uma interpretação de qualidade, como Brennan e Brown (1997); Napier e Spencer (2008); Nardi (2005); Russell (a) e Russell e Hale (2008).

No que concerne ao Brasil, Santos (2016) relata que o curso de Bacharelado em Letras-Libras da Universidade Federal de Santa Catarina alterou sua grade curricular para contemplar algumas disciplinas de laboratório em interpretação jurídica, no intuito de expor os alunos a determinadas problemáticas do contexto, fazendo com que se familiarizem com o meio e suas especificidades. Entretanto, Santos e Beer, na conclusão da resenha da obra de Russell (a), ressaltam que

[...] no Brasil o campo da interpretação de Língua Brasileira de Sinais (Libras) para o Português, e vice-versa em contextos jurídicos é incipiente, tanto no que se refere à pesquisa quanto à atuação propriamente dita. Tal área carece de pesquisas que evidenciem as principais demandas, dificuldades e desafios dos intérpretes nesse contexto específico de trabalho. Além disso, a necessidade de formação específica para os intérpretes de Libras-Português que atuam no contexto jurídico é urgente, uma vez que a comunidade surda tem cada vez mais buscado seus direitos (Santos e Beer 292).

Os resultados de uma pesquisa realizada por Roberson, Russell e Shaw (2011) apontam que intérpretes canadenses de língua de 
sinais recusam atuar no sistema da justiça devido à falta de treinamento especializado. Dentre as principais dificuldades e necessidades na atuação nesse contexto, Santos e Beer (291-2) ressaltam:

(i) a falta de pesquisas sobre a interpretação;

(ii) o predomínio da modalidade de interpretação simultânea em detrimento da modalidade consecutiva;

(iii) a falta de preparação junto aos participantes dos julgamentos;

(iv) lacunas nas tomadas de notas, o que torna difícil a reconstrução da mensagem; e

(v) a ausência de pesquisas em relação às experiências dos participantes envolvidos num processo judicial.

Santos (126-7), com base nas informações de seus colaboradores, destaca as seguintes dificuldades:

(i) desconhecimento do papel do intérprete pelo Judiciário;

(ii) tempo de duração das seções;

(iii) o fato de trabalhar sozinho;

(iv) a dificuldade de acesso a material prévio;

(v) a falta de previsão legal (orientações, normativas) sobre a atuação do intérprete de Libras-Português nesse meio;

(vi) ausência de competência referencial, entre outros.

Os participantes da pesquisa de Reckelberg (78), destacaram alguns pontos a serem incluídos em um curso de especialização:

(i) ética profissional;

(ii) postura frente ao judiciário;

(iii) terminologias jurídicas;

(iv) legislação;

(v) abordagem dos aspectos emocionais do intérprete para lidar com casos delicados. 
É possível notar que cada grupo investigado elencou temas distintos, abrindo um leque de pelo menos 16 quesitos a serem trabalhados em cursos de especialização. Diante dessas informações, buscou-se analisar alguns pontos listados por pesquisadores ou em designs já estabelecidos em determinadas formações internacionais, a fim de verificar se os pontos relacionados nas pesquisas brasileiras são contemplados.

Roberson, Russell e Shaw (2011) identificaram algumas habilidades necessárias, sugerindo pautas para as formações, tais como:

(1) prática nas diferentes modalidades de interpretação a partir da análise de um corpus de discursos;

(2) trabalho em equipe composta por surdos e ouvintes;

(3) orientação para o sistema legal;

(4) familiaridade ao discurso jurídico;

(5) investigação sobre os tipos de lei;

(6) protocolo de gravação de vídeo, qualificação, verificação de conflito de interesses, estratégias de preparação;

(7) preparação de casos;

(8) análise de mensagens e correção de erros.

Segundo Russell (b), a Associação de Intérpretes de Língua Visual do Canadá (AVLIC) definiu as competências, conhecimentos e habilidades necessários aos intérpretes atuantes em contexto jurídico:

(1) alto nível de proficiência nos pares linguísticos a serem trabalhados;

(2) altas habilidades em interpretação;

(3) conhecimento específico no âmbito da saúde mental, medicina e judiciário;

(4) compreensão do protocolo e do comportamento esperado em contextos legais;

(5) familiaridade com o discurso jurídico;

(6) comportamento profissional adequado ao trabalho em equipe, ao trato com os clientes e agentes do jurídico e à dinâmica intercultural. 
O JUSTISIGNS é um programa de treinamento educacional vocacional (VET - Vocational Educational Training) e desenvolvimento profissional contínuo (CPD - Continuous Professional Development) europeu, disponível online, que tem como objetivo identificar as competências para a interpretação de línguas de sinais em contextos legais. O projeto é coordenado pelo Interesource Group (Ireland) Limited e o representante legal do projeto é o Trinity College Dublin, na Irlanda. Vários parceiros institucionais e profissionais de alguns países europeus, como Suíça, Bélgica, Inglaterra, além do suporte da Universidade Gallaudet dos Estados Unidos, trabalham em conjunto para aprimorar a pesquisa com vistas a atender às necessidades da área. Dividido em 14 módulos, o programa apresenta os seguintes tópicos ${ }^{5}$ :

(1) Bases legais e glossário dos termos;

(2) análise comparativa de disposições e práticas atuais;

(3) resultados desejados;

(4) protocolos policiais;

(5) membros de comunidades surdas;

(6) línguas de sinais;

(7) interpretação: um caso especial de co-construção de significado;

(8) intérpretes de língua de sinais;

(9) esquema de controle-demanda;

(10) comunicando em interação triádica - preparação I;

(11) comunicando em interação triádica - durante um evento II;

(12) comunicando em interação triádica - post-hoc III;

5 (1) Legal Basis and Glossary of Terms ; (2) Benchmarking Current Provisions and Practices ; (3) Ideal Outcomes ; (4) Police Protocols ; (5) Deaf Community Members ; (6) Sign Languages ; (7) Interpreting: A special case of co-constructing meaning ; (8) Sign Language Interpreters ; (9) Demand-Control Schema ; (10) Putting it all together: Communicating within Triadic Exchanges I Preparation ; (11) Putting it all together: Communicating within Triadic Exchanges II - During an Event ; (12) Putting it all together: Communicating within Triadic Exchanges III - Post-Hoc ; (13) Working with Vulnerable Groups ; (14) Deaf Interpreters. 
(13) trabalhando com grupos vulneráveis;

(14) intérpretes surdos.

Ainda na Europa, a Universidade Paris 8 tem um curso específico para formar intérpretes de Língua de Sinais Francesa (LSF) que vão atuar diretamente nas instâncias jurídicas. Ele se configura em um diploma de estudo superior que equivale a uma graduação e a uma especialização de um ano, nomeada M1, num total de 4 anos de estudo. O currículo abrange as seguintes disciplinas, somando um total de 780 horas ( 660 h de ensino e 120 h de estágio prático, equivalente a $460 \mathrm{~h}$ de teoria $+60 \mathrm{~h}$ de estágio prático em Língua de Sinais Francesa e $210 \mathrm{~h}$ de teoria $+60 \mathrm{~h}$ de estágio prático em interpretação jurídica profissionalizante):

$\mathrm{O}$ ensino da língua compreende os aspectos linguísticos do nível básico ao avançado. A parte específica é distribuída da seguinte forma:

\section{Glossário especializado em LSF [60 h $]^{6}$}

- Léxico jurídico em LSF,

- Trabalhos de aplicação.

\section{Direito, práticas judiciais e litigantes surdos [60 horas $]^{7}$}

- História e prática do direito: o quadro legislativo aplicável às pessoas com deficiência, história do direito dos surdos, textos e jurisprudência específica,

\footnotetext{
${ }^{6}$ [Lexique spécialisé LSF] Lexique juridique en LSF ; Travaux d'application.

${ }^{7}$ [Droit, pratiques judiciaires et justiciables sourds] Histoire et pratique du droit : le cadre législatif applicable aux personnes handicapées, histoire du droit des sourds, textes et jurisprudences spécifiques ; Particularismes des pratiques : droit de la famille, droit du travail, procédure pénale, droits des sourds en prison, dettes et surendettement, problèmes de voisinage, droits des étrangers sourds, violences faites aux femmes ; Problématiques récurrentes : discrimination, harcèlement ; Acteurs et partenaires : nature et fonction des experts, rôle de l'interprète / interface, partenaires institutionnels.
} 
- Particularidades das práticas: direito da família, direito do trabalho, processo penal, direitos dos surdos na prisão, dívidas e superendividamento, problemas de vizinhança, direitos dos surdos estrangeiros, violência contra a mulher,

- Questões recorrentes: discriminação, assédio,

- Atores e parceiros: natureza e função dos especialistas, papel do intérprete/interface, parceiros institucionais.

\section{Cultura Surda $[30 \text { horas }]^{8}$}

- História dos surdos;

- Apresentação da surdez;

- Especificidade do público.

\section{Ambiente profissional [60 horas $]^{9}$}

- Estruturas sociais, médicas e médico-psicológicas;

- Dificuldades e técnicas de integração;

- Profissionalidade dos surdos;

- Compensação: ajuda ao público surdo;

- Organização de uma municipalidade e funcionamento dos serviços;

- Procedimentos públicos;

- Funcionamento em rede;

- Construção do projeto individual.

${ }^{8}$ [Culture Sourde] Histoire des sourds ; Présentation de la surdité ; Spécificité du public.

${ }^{9}$ [Environnement professionnel] Structures sociales, médicales et médico-psychologiques ; Difficultés et techniques d'intégration ; Professionnelle des sourds ; Compensation : les aides au public sourd ; Organisation d'une municipalité et fonctionnement des services ; Procédures publiques ; Fonctionnement en réseau ; Construction du projet individuel.

Cad. Trad., Florianópolis, v. 40, n 2, p. 252-281, mai-ago, 2020. 


\section{Estágios práticos $[120 \mathrm{~h}]^{10}$}

- Estágio de 2 a 3 semanas de imersão linguística em LSF;

- Estágio de 1 a 2 semanas de permanência em ambiente jurídico.

Ao comparar-se o design curricular do curso francês aos quesitos e temáticas elencados pelos autores anteriormente relacionados, constata-se que não foram contempladas abordagens como a ética profissional, as modalidades de interpretação (simultânea, consecutiva ou intermitente) e os tipos de registros (anotações e vídeos) adotados em campo. Vale questionar se a carga horária dessa formação é suficiente para desenvolver ao mesmo tempo tanto o aprendizado da língua como a interpretação profissionalizante.

Comparada ao curso de Bacharelado da Universidade Federal de Santa Catarina, que possui uma carga horária total de 3.708 horas-aula, essa formação parece insuficiente. Só a disciplina de laboratório em contexto jurídico do Bacharelado Letras-Libras da UFSC soma o total de $144 \mathrm{~h} / \mathrm{a}$, ou seja, em torno de 40 horas a menos que todo o quadro formativo específico ao contexto jurídico da Universidade de Paris 8 (somadas as partes teórica e prática).

Infelizmente, a questão curricular não será aprofundada neste artigo, mas abordá-la é importante no sentido de que ela traz elementos para futuras discussões e reflexões. De acordo com Santos e Sutton-Spence (266),

no caso brasileiro, pondera-se sobre a necessidade de reunir esforços de todos os envolvidos - intérpretes, comunidade surda e poder público - e multiplicar ações inovadoras que, com base na legislação existente, visem à profissionalização de intérpretes de Libras-Português nos contextos jurídicos.

${ }^{10}$ [Stages pratiques] Stage de 2 à 3 semaines en bain de langue LSF ; Stage de 1 à 2 semaines en permanence d'accueil juridique.

Cad. Trad., Florianópolis, v. 40, n 2, p. 252-281, mai-ago, 2020. 
Portanto, a criação de um design curricular, o nível de formação (graduação ou pós-graduação), a conscientização do sistema judiciário em relação à pessoa e à atuação do profissional intérprete, que tipos de organismos necessários para colher as demandas, formalizar a presença e encaminhar o profissional nas diferentes instâncias, entre outros pontos, precisam ser discutidos coletivamente.

\section{Considerações finais}

Como as pesquisas são ainda muito recentes, poucos esforços foram feitos até agora no que consiste à organização de formações e especializações de intérpretes do par Português-Libras (ou ainda outras línguas de sinais) para atuação no contexto jurídico aqui no Brasil. Além disso, ainda não é consenso entre os autores que as modalidades de interpretação e os recursos auxiliares são passíveis de trazer melhores resultados, assim como a consequente diminuição de erros. A esse respeito recomenda-se as discussões de Russell ((a), (b)); Napier (2011); Mathers (2007); Fournier (1997) e Santos e Sutton-Spence (2018).

Outras questões carecem ainda de investigação, sobretudo em relação à sobreposição de elementos como saúde emocional e psicológica envolvidas nos processos legais, não somente em relação às partes envolvidas como aos próprios intérpretes, uma vez que situações de litígios envolvem altos níveis de estresse e instabilidade emocional, por exemplo.

Os intérpretes também devem estar preparados para lidar com a diversidade de clientes e seus diferentes modos de se expressar e comunicar. Relatos demonstraram a necessidade de intérpretes surdos na equipe, visto que, devido à sua convivência em diversos contextos de sinalização e contato com diferentes variantes, eles, possivelmente, estejam bem preparados para contornar as dificuldades de comunicação resultantes de diversas variáveis sociolinguísticas.

Pode-se, ainda, acrescentar a importância de vídeos registros de depoimentos e sessões que possam ser utilizados como ferramen- 
ta de consulta e como corpus para a prática dos profissionais em formação. Há de se pensar também nas "questões de ordem operacional (como proceder diante de uma convocação, qual posicionamento adotar no lugar reservado a este profissional - se próximo ao juiz, delegado ou advogado), dentre outras" (Santos 118).

Este trabalho, enquanto prática discursiva em torno da interpretação intermodal jurídica, visou fortalecer outros discursos já proferidos por outros autores e pesquisadores. Trata-se, também, de reforçar a urgência da construção dessa especialidade. O desafio é enorme, a tarefa imensa e a responsabilidade complexa, haja vista que envolve questões profissionais, técnicas, éticas, políticas e de direitos sociais, linguísticos e humanos.

\section{Referências}

Baigorri-Jalón, Jesús. From Paris to Nuremberg: The birth of conference interpreting. Trad. para o Inglês por Holly Mikkelson and Barry Slaughter Olsen. Amesterdã, Filadélfia: John Benjamins Publishing Company, 2014.

Berthier, Ferdinand. Le Code Napoléon, code civil de l'Empire français mis à la portée des sourdsmuets et de leurs familles et des parlants en rapport journalier avec eux. Paris, Librairie du Petit journal, 1868. Disponível em: < https://gallica. bnf.fr/ark:/12148/bpt6k56799809.r =institut \%20des \%20sourds \% 20au \% 20 br\%C3\%A9sil?rk=407727;2>. Acesso em: 08 de abril de 2019 .

Brasil. Decreto $n^{\circ}$ 8.332, de 3 de Novembro de 1910. Approva o Codigo do Processo Civil e Commercial do Distrito Federal. Diário Oficial da União, República Federativa do Brasil, Atos do Poder Legislativo, Brasília, DF, 04 nov. 1910, p. 9.200. Disponível em: < https://www2.camara.leg.br/legin/fed/ decret/1910-1919/decreto-8332-3-novembro-1910-498462-publicacaooriginal-1pe.html >. Acesso em: 17 de abril de 2019. 
Brasil. Decreto $n^{\circ}$ 16.752, de 31 de Dezembro de 1924. Põe em execução o Codigo do Processo Penal no Distrito Federal. Diário Official - 4/1/1925, p. 220. Coleção de Leis do Brasil - 1924, p. 262, v. IV. Disponível em: < https://www2. camara.leg.br/legin/fed/decret/1920-1929/decreto-16752-31-dezembro-1924516249-publicacaooriginal-139889-pe.html > . Acesso em: 17 de abril de 2019.

Brasil. Decreto-Lei 3.689, de 3 de outubro de 1941. Dispõe sobre o Código de Processo Penal. Diário Oficial da União, República Federativa do Brasil, Atos do Poder Legislativo, Brasília, DF, 13 out. 1941. Ano CXXXIX, Seção 1, p.19.699. Disponível em: <https://www2.camara.leg.br/legin/fed/declei/1940-1949/ decreto-lei-3689-3-outubro-1941-322206-publicacaooriginal-1-pe.html > . Acesso em: 17 de abril de 2019.

Brasil. Decreto-Lei $n^{\circ} 5.452$ de $1^{\circ}$ de Maio de 1943. Aprova a Consolidação das Leis do Trabalho. Diário Oficial da União - Seção 1 - 9 ago. 1943, p. 11.937. Disponível em: < https://www2.camara.leg.br/legin/fed/declei/1940-1949/decretolei-5452-1-maio-1943-415500-norma-pe.html > . Acesso em: 10 de abril de 2019.

Brasil. Lei Ordinária $n^{\circ} 10792$ de $1^{\circ}$ de dezembro de 2003. Altera a Lei $\mathrm{n}^{\circ}$ 7.210, de 11 de junho de 1984 - Lei de Execução Penal e o Decreto-Lei no 3.689 , de 3 de outubro de 1941 - Código de Processo Penal e dá outras providências. Diário Oficial da União - Seção 1 - 2 dez. 2003, p. 2. Disponível em: <https:// www2.camara.leg.br/legin/fed/lei/2003/lei-10792-1-dezembro-2003-497216publicacaooriginal-1-pl.html $>$.

Brasil. Decreto 5.626 de 22 de dezembro de 2005. Regulamenta a Lei n o 10.436, de 24 de abril de 2002, que dispõe sobre a Língua Brasileira de Sinais - Libras, e o art. 18 da Lei no 10.098, de 19 de dezembro de 2000. Diário Oficial da União - Seção 1 - 23/12/2005, p. 28.

Brasil. Lei $n^{\circ} 12.319$, de 01 de setembro de 2010. Dispõe sobre a regulamentação da profissão de Tradutor e Intérprete da Língua Brasileira de Sinais - Libras. Diário Oficial da União, República Federativa do Brasil, Atos do Poder Legislativo, Brasília, DF, 2 set. 2010. n 169, ano CXXXIX, Seção 1, p. 43.

Brasil. Lei no 13.105 , de 16 de março de 2015. Código de Processo Civil. Diário Oficial da União - Seção 1 - 17 mar. 2015, Página 1. Disponível em: <https:// www2.camara.leg.br/legin/fed/lei/2015/lei-13105-16-marco-2015-780273norma-pl.html > . Acesso em: 10 de abril de 2019. 
Brasil. Resolução $n^{\circ}$ 230, de 22 de junho de 2016. Diário da Justiça [do] Conselho Nacional de Justiça, Brasília, DF, nº 106, p. 6-13, 23 jun. 2016.

Brennan, Mary. "Signs of Injustice”. The Translator. 5(2), (1999): 221-246.

Brennan, Mary and Brown, Richard. Equality before the law: Deaf people's access to Justice. Coleford, England: Douglas McLean, 1997.

Capanema-Souza, Sylvio. "O Código Napoleão e sua influência no Direito brasileiro". Revista da EMERJ. v. 7, $\mathrm{n}^{\circ} .26$ (2004): 36-51. Disponível em: < http://www.emerj.tjrj.jus.br/revistaemerj_online/edicoes/revista26/ revista26_36.pdf >. Acesso em: 10 de abril de 2019.

Declaração Universal dos Direitos Humanos. Assembleia Geral das Nações Unidas em Paris. 10 dez. 1948. Disponível em: < https://www.ohchr.org/EN/ UDHR/Pages/Language.aspx?LangID = por $>$. Acesso em: 26 de junho de 2015.

Delisle, Jean; Woodsworth, Judith (Orgs.) Translators through History. Amesterdã, Filadélfia: John Benjamins Publishing Company, 2012.

Fournier, Christiane. "L'interprétation pour sourds au pénal en France". L'interprétation en langues des signes. v. 42, $\mathrm{n}^{\circ}$. 3, set. (1997): 533-545. Disponível em: <https://id.erudit.org/iderudit/002764ar > Acesso em: $08 \mathrm{de}$ abril de 2019.

França. Code d'instruction criminelle, 19 de novembro de 1808. Tratado de instrução criminal e processo penal: Paris, 1808. Disponível em: < https:// ledroitcriminel.fr/la_legislation_criminelle/anciens_textes/code_instruction_ criminelle_1929.htm $>$ Acesso em: 17 de abril de 2020 .

Ginezi, Lucia Latarini. "A ética na interpretação de tribunal: o Brasil no banco dos réus”. TradTerm. São Paulo, v. 20, dez. (2012): 27-42. Disponível em:<http:// www.revistas.usp.br/tradterm/article/view/49040>. Acesso em: 08 de abril de 2019.

Haensch, Günther. "Técnica y picardía del intérprete diplomático". Conferência pronunciada em 22 de março de 1965 no Instituto de Cultura Hispânica de Madri. München: Max Hueber, 1965. 
Justisigns Consortium. VET in Interpreting and Justice. Ensuring equality \& access for the deaf community in interpreted police settings. IGI Education, Dublin, 2016. Disponível em: <http://www.justisigns.com/JUSTISIGNS Project/Course.html > . Acesso em: 17 de abril de 2019.

Kelsen, Hans. Teoria Pura do Direito. Trad.: J. Baptista Machado, Teoria Pura do Direito. São Paulo: Martins Fontes, [1960] 1998.

Lee, Jieun. "Court interpreting". In: Mikkelson, H.; Jourdenais, R. (Ed.). The Routledge Handbook of Interpreting. Londres e Nova York: Routledge, 2015, p. 186-201.

Mathers, Carla. Sign language interpreters in court: Understanding best practices. Bloomington/Milton Keynes: Authorhouse, 2007.

Miller, Katrina. "Access to Sign Language Interpreters in the Criminal Justice System". American Annals of the Deaf. 146(4), (2001): 328-330.

Miller, Katrina; McCay, Vernon. "Qualifications of Sign Language Interpreters in the Criminal Justice System". Journal of Interpretation. (1994): 111-124.

Napier, Jemina. "Signed language interpreting". In: Windle, Kirsten; Kevin, Malmkjaer. (Eds). The Oxford Handbook of Translation Studies. Oxford, UK: Oxford University Press, 2011.

Napier, Jemina; Spencer, David. "Guilty or Not Guilty? An Investigation of Deaf Jurors' Access to Court Proceedings Via Sign Language Interpreting”. In: Russell, Debora; Hale, Sandra. (Eds.). Interpreting in Legal Settings. Washington, DC: Gallaudet University Press, 2008.

Nardi, Marco. "Vulnerable Groups - Deaf People at Official Hearings. A Perspective of the European Forum of Sign Language Interpreters". In: KiejzerLambooy, H.; Gasille, W. J. (Eds.). Aequilibrium: Instruments for Lifting Language Barriers in Intercultural Legal Proceedings. Utrecht, Netherlands: ITV Hogeschool voor Tolken en Vertalen, 2005, p. 69-76. 
Napier, Jemina. "Comparing signed and spoken language interpreting". In: Mikkelson, H.; Jourdenais, R. (Ed.). The Routledge Handbook of Interpreting. Londres e Nova York: Routledge, 2015, p. 129-43.

Núñez, Gabriel. González. Translating for linguistic minorities: translation policy in the United Kingdom. Tese de Doutorado em Estudos da Tradução e Estudos Interculturais, Departamento de Estudos Ingleses e Germânicos. Universidade de Rovira i Virgili. Tarragona, Espanha, 2014.

Ozolins, Uldis(a). "Interpreting and Translating in Australia". Current Issues and International Comparisons. Melbourne: Language Australia, 1998.

Ozolins, Uldis(b). "Communication Needs and Interpreting in Multilingual Settings: the International Spectrum of Response". In: Roberts, R. et al (Org.). The critical link 2: interpreters in the Community. Amesterdã, Filadélfia: John Benjamins Publishing Company, 2000.

Queiroz, Guilherme; Bagno, Marcos; Monteiro, Julio. "A tradução como política linguística: o caso da UNASUL". Trab. Ling. Aplic. Campinas, ${ }^{\circ}$. 57.1, jan./ abr, (2018): 127-154.

Reckelberg, Saimon. Intérpretes de Libras-Português no Contexto Jurídico: uma investigação dos serviços de interpretação oferecidos na Grande Florianópolis. Trabalho de Conclusão de Curso em Bacharelado Letras Libras. Florianópolis: Universidade Federal de Santa Catarina, 2018.

Roberson, Len.; Russell, Debra.; Shaw, Risa. "Legal Interpreting: A North American Survey". In: Costello, Brendan.; Thumann, Mary.; Shaw, Risa. World Association of Sign Language Interpreters. Proceedings of the 4th Conference of the World Association of Sign Language Interpreters. Durban, South Africa, July 14-16 (2011): 65-99.

Russell, Debra (a). Interpreting in legal contexts: Consecutive and simultaneous interpretation. Burtonsville, MD: Linstock Press, 2002.

Russell, Debra(b). Interpreting legal discourse \& working in legal settings. Association of Visual Language Interpreters of Canada. AVLIC Publications, 2011. Disponível em: <http://www.avlic.ca/sites/default/files/docs/AVLIC- 
Interpreting_Legal_Discourse\%26Working_in_Legal_Settings.pdf $>$.Acesso em: 08 de abril de 2019 .

Russell, Debra; Hale, Sandra. (Eds). Issues in legal interpretation [Studies in interpretation 7]. Gallaudet Press: Washington, DC, 2008.

Santos. Silvana Aguiar. dos. "Questões emergentes sobre a interpretação de libras-português na esfera jurídica”. Revista Belas Infiéis. v. 5, nº 1 (2016): 117 129. Disponível em: <http://periodicos.unb.br/index.php/belasinfieis/article/ view/19511 > . Acesso em: 08 de abril de 2019.

Santos. Silvana Aguiar. dos; Beer, Hanna. "Interpreting in legal contexts: Consecutive and simultaneous interpretation". Cadernos de Tradução. v. 37, n. 2 (2017): 288-293. Disponível em: < https://periodicos.ufsc.br/index.php/traducao/ article/view/2175-7968.2017v37n2p288 > . Acesso em: 08 de abril de 2019.

Santos. Silvana Aguiar. dos; Francisco, Camila. "Políticas de tradução: um tema de políticas linguísticas?". Forum linguístico. Florianópolis, v. 15, n. 1, jan./mar. (2018): 2939-2949. Disponível em: < https://periodicos.ufsc.br/index.php/forum/ article/view/1984-8412.2018v15n1p2939> . Acesso em: 08 de abril de 2019.

Santos. Silvana Aguiar. dos; Sutton-Spence, Rachel. "A profissionalização de intérpretes de línguas de sinais na esfera jurídica”. Translatio. Porto Alegre, $\mathrm{n}^{0}$. 15, jun. (2018): 264-89. Disponível em: < https://seer.ufrgs.br/translatio/ article/view/80945 > . Acesso em: 08 de abril de 2019.

Stevens, Helga. "Justice Must Be Seen to Be Done”. In: Kiejzer-Lambooy, H.; Gasille, W. J. (Eds.). Aequilibrium: Instruments for Lifting Language Barriers in Intercultural Legal Proceedings. Utrecht, Netherlands: ITV Hogeschool voor Tolken en Vertalen, 2005, 77-86.

Stone, Christopher. "Interpreting”. In: Pfau, Roland; Steinbach, Markus; Woll, Bencie. (Eds). Handbook of Sign Language Linguistics. Amsterdam: De Gruyter Mouton, 2012, p. 980-998.

Stone, Christopher; Woll, Bencie. "Dumb O Jemmy and others: Deaf people, interpreters, and the London Courts in the eighteenth and nineteenth centuries". Sign language studies. 8(3), (2008): 226-40. 
Tilbury, Nadine. "Specific Attention for Vulnerable Groups - In Particular Those with Hearing Impairments and Sign Language Users - Legislation, Practical Issues and Training". In: Kiejzer-Lambooy, H.; Gasille, W.J. (Eds.). Aequilibrium: Instruments for Lifting Language Barriers in Intercultural Legal Proceedings. Utrecht, Netherlands: ITV Hogeschool voor Tolken en Vertalen, 2005, p. 61-68.

Turner, Graham. "The Bilingual, Bimodal Courtroom: At First Glance”. Journal of Interpretation. 7(1), (1995): 3-34.

Turner, Graham; Brown, Richard. "Interaction and the Role of the Interpreter in Court”. In: Harrington, F.J; Turner, Graham. (Eds.). Interpreting Interpreting: Studies and Reflections on Sign Language Interpreting. Coleford, UK: Douglas McLean, 2001, p. 152-167.

Universidade Paris 8. Service Formation Permanente. Information et accompagnement juridiques en LSF - DESU. Disponível em: < http://www. fp.univ-paris8.fr/IMG/article_PDF/Information-juridique-LSF.pdf $>$. Acesso em 17 de abril de 2019.

Wilcox, Phyllis. "Dual Interpretation and Discourse Effectiveness in Legal Settings". Journal of Interpretation. 7(1), (2006): 89-98.

Recebido em: 06/01/2020

Aceito em: 27/03/2020

Publicado em maio de 2020

Rosemeri Bernieri de Souza. E-mail: bernieri.rose@gmail.com. ORCID: http:// orcid.org/0000-0001-6812-856X. O presente trabalho foi realizado com apoio da Coordenação de Aperfeiçoamento de Pessoal de Nível Superior - Brasil (CAPES) - Código de Financiamento 001 